\title{
A single NFкB system for both canonical and non-canonical signaling
}

\author{
Vincent Feng-Sheng Shih ${ }^{1}$, Rachel Tsui ${ }^{1}$, Andrew Caldwell ${ }^{1}$, Alexander Hoffmann ${ }^{1}$ \\ ${ }^{I}$ Signaling Systems Laboratory and San Diego Center for Systems Biology, Department of Chemistry and Biochemistry, University \\ of California, San Diego, 9500 Gillman Dr, La Jolla, CA 92093, USA
}

Two distinct nuclear factor кB (NFкB) signaling pathways have been described; the canonical pathway that mediates inflammatory responses, and the non-canonical pathway that is involved in immune cell differentiation and maturation and secondary lymphoid organogenesis. The former is dependent on the IкB kinase adaptor molecule NEMO, the latter is independent of it. Here, we review the molecular mechanisms of regulation in each signaling axis and attempt to relate the apparent regulatory logic to the physiological function. Further, we review the recent evidence for extensive cross-regulation between these two signaling axes and summarize them in a wiring diagram. These observations suggest that NEMO-dependent and -independent signaling should be viewed within the context of a single NFKB signaling system, which mediates signaling from both inflammatory and organogenic stimuli in an integrated manner. As in other regulatory biological systems, a systems approach including mathematical models that include quantitative and kinetic information will be necessary to characterize the network properties that mediate physiological function, and that may break down to cause or contribute to pathology.

Keywords: NFkB; inflammation; immune response; immune development; mathematical model; signaling crosstalk Cell Research (2011) 21:86-102. doi:10.1038/cr.2010.161; published online 23 November 2010

\section{Introduction}

Nuclear factor $\kappa \mathrm{B}(\mathrm{NF} \kappa \mathrm{B})$ is a critical transcription factor involved in a broad range of biological processes, including immune responses, cell survival, stress responses and maturation of various cell types. While $\mathrm{NF \kappa \textrm {B }}$ activation is required to protect organisms from environmental effects, misregulated NFKB activity is often observed in various diseases including chronic inflammation and cancer. Thus, understanding the regulation of NFKB signaling is important for maintaining human health.

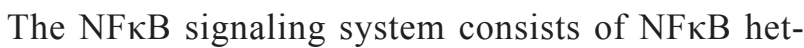
erodimers or homodimers of Rel homology domain (RHD)-containing polypeptides and their stoichiometric inhibitor proteins, I $\mathrm{B} B$ (Figure 1). The RHD within the five monomers - RelA, RelB, cRel, p50 and p52 - mediates dimerization, DNA binding, interaction with $\mathrm{I} \kappa \mathrm{Bs}$ and nuclear translocation. The five monomers form 15

Correspondence: Alexander Hoffmann

E-mail: ahoffmann@ucsd.edu potential dimers. Generation of all monomers is transcriptionally regulated, but p50 and p52 are also regulated by processing of precursor proteins $\mathrm{p} 105$ and p100, respectively. Thus, different NFкB dimeric complexes are expressed cell type- and stimulus-specifically; some of the physiologically important dimers are RelA:p50, cRel:p50 and RelB:p52.

The classical inhibitor proteins in the NFKB signaling system consist of the single polypeptide I $\mathrm{KBs}$ : $\mathrm{I} \kappa \mathrm{B} \alpha$, $\mathrm{I} \kappa \mathrm{B} \beta$ and $\mathrm{I} \kappa \mathrm{B} \varepsilon$. In resting cells, I $\mathrm{KB}$ binds and sequesters $\mathrm{NF} \kappa \mathrm{B}$ dimer and prevents DNA binding and transcriptional activation. Stimulus-responsive activation of the I $\kappa B$ kinase (IKK) results in the degradation of the I $\kappa$ Bs to release and activate NFKB (Figure 2). Synthesis of

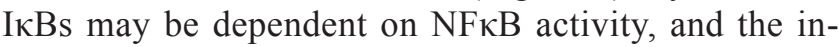
ducible activation of IкBs results in negative feedback. Classical I $\kappa$ Bs are characterized by their ankyrin repeats domain (ARD) that sequesters NFkB into a latent state. Recently, it was found that 100 , when present in a multimeric complex, may also mediate $\mathrm{NF \kappa B}$ inhibition in trans; this activity was termed $\mathrm{I} \kappa \mathrm{B} \delta$ [1]. Moreover, size exclusion chromatography analyses suggest that I $\mathrm{I} B \delta$ activity is mediated by a $\sim 650 \mathrm{kDa}$ high molecular weight 


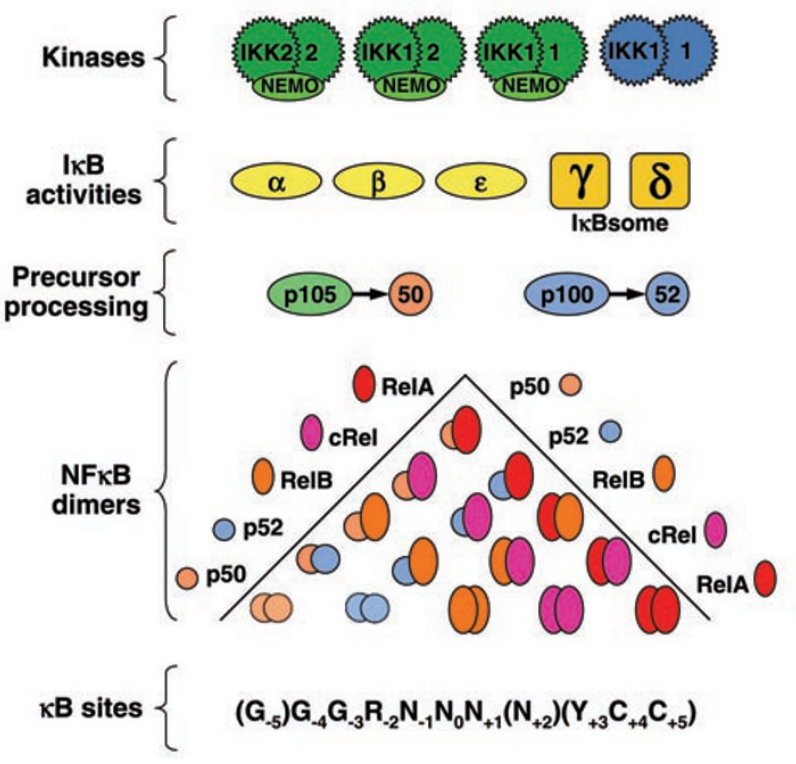

Figure 1 Components of the IKK-I $\mathrm{KB}-\mathrm{NF} \kappa \mathrm{B}$ signaling system. The IKK form canonical NEMO-containing (green) complexes and non-canonical (blue) complexes, which control the degrada-

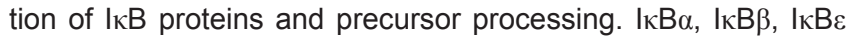
and the $I \kappa B$ activities within the $I \kappa B$ some $I \kappa B \gamma$ and $I \kappa B \delta$ are able to sequester $\mathrm{NF} \kappa \mathrm{B}$ dimers. The $\mathrm{p} 50$ and $\mathrm{p} 52 \mathrm{NF} \kappa \mathrm{B}$ proteins are generated from the processing of newly synthesized precursor proteins $\mathrm{p} 105$ and $\mathrm{p} 100$, respectively. The five $\mathrm{NF} K \mathrm{~B}$ family members (RelA/p65, cRel, RelB, p52 and p50) can potentially form 15 heterodimers and homodimers that can bind to a large number of $\kappa B$ sites in DNA, which are characterized by a remarkably broad sequence consensus.

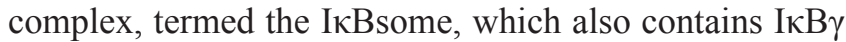
activity from $\mathrm{p} 105$ protein [2]. The pathways that govern IкBsome assembly and degradation are critical for regulating $\mathrm{NF \kappa B}$ activity [3].

Activation of NFKB results in the induction of a variety of inflammatory, developmental and survival genes. The rapid and reversible inflammatory and immune response typically occurs through the activation of the canonical pathway, while the slower and irreversible developmental response typically occurs through the noncanonical pathway. These two pathways are thought to be fundamentally distinct. While the canonical pathway is mediated through the activation of a NEMO (IKK $\gamma$ )dependent IKK, the non-canonical pathway is classically defined as being mediated through the activation of a NEMO-independent kinase complex involving IKK1 and the NFкB-inducing kinase (NIK) [4]. In the canonical pathway, pre-existing, latent $\mathrm{NF \kappa B}$ dimers are released from classical IkBs. In the non-canonical pathway, new

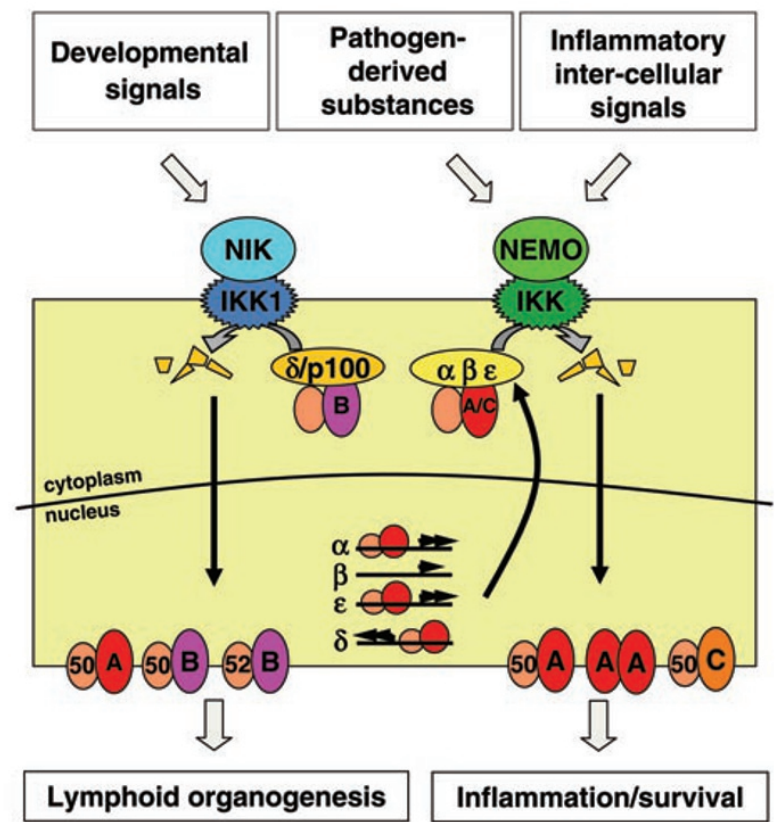

Figure 2 The NFKB signaling module consisting of canonical and non-canonical pathways. The non-canonical pathway is activated through developmental signals activating NIK/IKK1. This activation results in the degradation of $I \kappa B \delta$ and processing of p100 and allows the nuclear translocation of RelA:p50, RelB:p50 and RelB:p52 dimers, which activate genes responsible for organ development. The canonical pathway is activated through pathogen and inflammatory signals activating NEMO/ IKK. This activation results in the degradation of $|\kappa B \alpha / / \kappa B \beta /| \kappa B \varepsilon$, allowing for the nuclear translocation of RelA:p50, RelA:RelA and cRel:p50 dimers, which then activate genes responsible for inflammation and survival.

synthesis of p100 and RelB allows for generation of RelB:p52 which is insensitive to I $\kappa \mathrm{B}$ control and thus localized to the nucleus.

Though canonical and non-canonical pathways are generally thought to be distinct, recent studies have revealed numerous crosstalk mechanisms that connect them. This crosstalk involves expression control of NF $\kappa B$ monomers, interdependent proteolytic processing events of precursors and the newly identified I $\kappa \mathrm{B} \delta$ activity that is inducibly expressed by one pathway and inducibly degraded by another.

This review first describes the distinct characteristics of the canonical and non-canonical pathways and then discusses extensive cross-regulatory mechanisms that suggest that the regulation of $\mathrm{NF \kappa B}$ dimers is in fact mediated by a single NFאB signaling system, and ought to be investigated through systems-level analysis. 


\section{The canonical pathway}

The canonical NFkB pathway is defined as being mediated by a NEMO-dependent IKK; in contrast, the noncanonical pathway is defined as not requiring NEMO. Genetic deletion of NEMO resulted in embryonic lethality as a result of massive apoptosis in the fetal liver [5]. The fact that the IKK2 knockout [6] and the RelA knockout [7] showed a similar phenotype led to the broadly accepted model of a signaling axis of NEMO-IKK2-RelA, termed the canonical pathway. However, recent work suggests that IKK1 plays a role in the canonical pathway as well, and may compensate for the loss of IKK2 within the NEMO-dependent kinase [8]. Conversely, NEMOindependent IKK2 functions have also been suggested [9]. We therefore suggest that only NEMO dependence strictly defines the canonical pathway. However, given the close functional association of IKK2 with NEMO in the literature, our current understanding of canonical activation is in large part limited to the activation of IKK2. Similarly, RelA was recently shown to be activated by the non-canonical activation mechanism [1] and thus should not be viewed as the exclusive effector of the canonical pathway; however, our current understanding of RelA function is largely limited to canonical signaling.

The canonical NFKB pathway is activated by proinflammatory signals such as cytokines, pathogen-associated molecular patterns (PAMPs), and some danger-associated molecular patterns (DAMPs). Upon cellular exposure to these agents, extracellular and intracellular receptors trigger the activation of NEMO-containing kinase complexes through the recruitment of various proteins involved in ubiquitin chain formation. IKK2 is activated by phosphorylation at serine (Ser) 177 and Ser181 [10]. Emerging evidence indicates that three possible pathways for IKK2 activation are utilized to varying degrees by different inflammatory receptors (Figure 3 ). In the case of the TNF receptor I, associated proteins recruit the E2/E3 ligase complex consisting of UbcH5 and cIAP1, which subsequently forms ubiquitin chains of various linkages to RIP1 $[11,12]$. The TAB/TAK1 and IKK complexes are able to bind these ubiquitin chains, allowing the activated TAK1 to phosphorylate and activate IKK2 [13]. Additionally, oligomerization of the NEMO-IKK2 complex upon mixed ubiquitin chain binding can allow for TAK1-independent trans-autophosphorylation and activation of the IKK2 complex [12]. Another pathway of IKK2 activation revolves around linear ubiquitin chain formation. In the context of TNF signaling, the receptorassociated proteins TRADD, tumor necrosis factor receptor-associated factor (TRAF) 2 and cIAP1/2 recruit LUBAC, an ubiquitin ligase complex consisting of HOIP and HOIL-1L [14]. LUBAC conjugates linear-linked ubiquitin chains to NEMO, which results in IKK activation, possibly through trans-autophosphorylation [15]. In the third pathway of IKK2 activation, ligand engagement of the IL-1R and TLRs leads to the recruitment of the E2/E3 ligase complex made up of Ubc13 and TRAF6 [16]. This complex conjugates K63-linked ubiquitin chains to IRAK1, allowing for TAK1 and IKK2 complex binding and subsequent TAK1 activation of IKK2 through phosphorylation [12]. While a molecular description of these three pathways has advanced, the stimulus specificity of each pathway remains to be delineated.

Once canonical IKK is activated, it phosphorylates and designates the classical I $\mathrm{BBs}(\mathrm{I} \kappa \mathrm{B} \alpha, \mathrm{I} \kappa \mathrm{B} \beta$ and $\mathrm{I} \kappa \mathrm{B} \varepsilon)$ for degradation releasing NFKB into the nucleus (Figure 4). The phosphorylation of the canonical I $\mathrm{KB} \alpha$ on the N-terminal serines (Ser32/36) allows for the recruitment of the E3 ubiquitin ligase SCF/BTRCP, thus marking it for degradation via the $26 \mathrm{~S}$ proteasome [17]. This ubiquitination

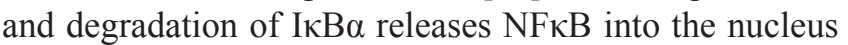
and allows transcriptional activation to occur. Similar phosphorylations occur on $\mathrm{I} \kappa \mathrm{B} \beta$ and $\mathrm{I} \kappa \mathrm{B} \varepsilon$ upon canonical IKK activation resulting in degradation of these IкBs and release of NFKB into the nucleus. Interestingly, the molecular determinants for the enzymatic specificity of the canonical IKK complex for classical IкB proteins are not yet understood.

The primary NFKB effectors of the canonical pathway are transactivation domain-containing polypeptides RelA/p65 and cRel, which form either homodimers or heterodimers with the transactivation domain-lacking p50. Thus, four transcriptional activators (RelA:RelA, RelA:p50, cRel:cRel, cRel:p50) are potentially activated in response to stimuli of the canonical pathway. The phenotypes of genetic ablation studies of the constituent polypeptides are largely correlated with their tissue distribution. Thus, these studies showed an essential role for cRel in B- and T-lymphocyte functions, cell types in which it is highly expressed. $\mathrm{crel}^{-/-}$mice are not lethal but show several defects, including defects in the cell cycle progression and survival in B cells, defects in CD4 and CD8 T-cell responses, and impaired cytokine production $[18,19]$. Further, dendritic cells lacking cRel:p50 are defective in CD40L-induced cell survival [20] and displayed reduced maturation phenotype [21]. However, the results from domain mutation studies are not fully explained: removal of the $\mathrm{C}$-terminal activation domain of cRel results in enlarged lymph nodes and lymphoid hyperplasia [22].

In contrast, deficiency of the ubiquitously expressed RelA/p65 protein in rela ${ }^{-/-}$mice results in embryonic lethality due to massive apoptosis in the fetal liver [7, 23]. 


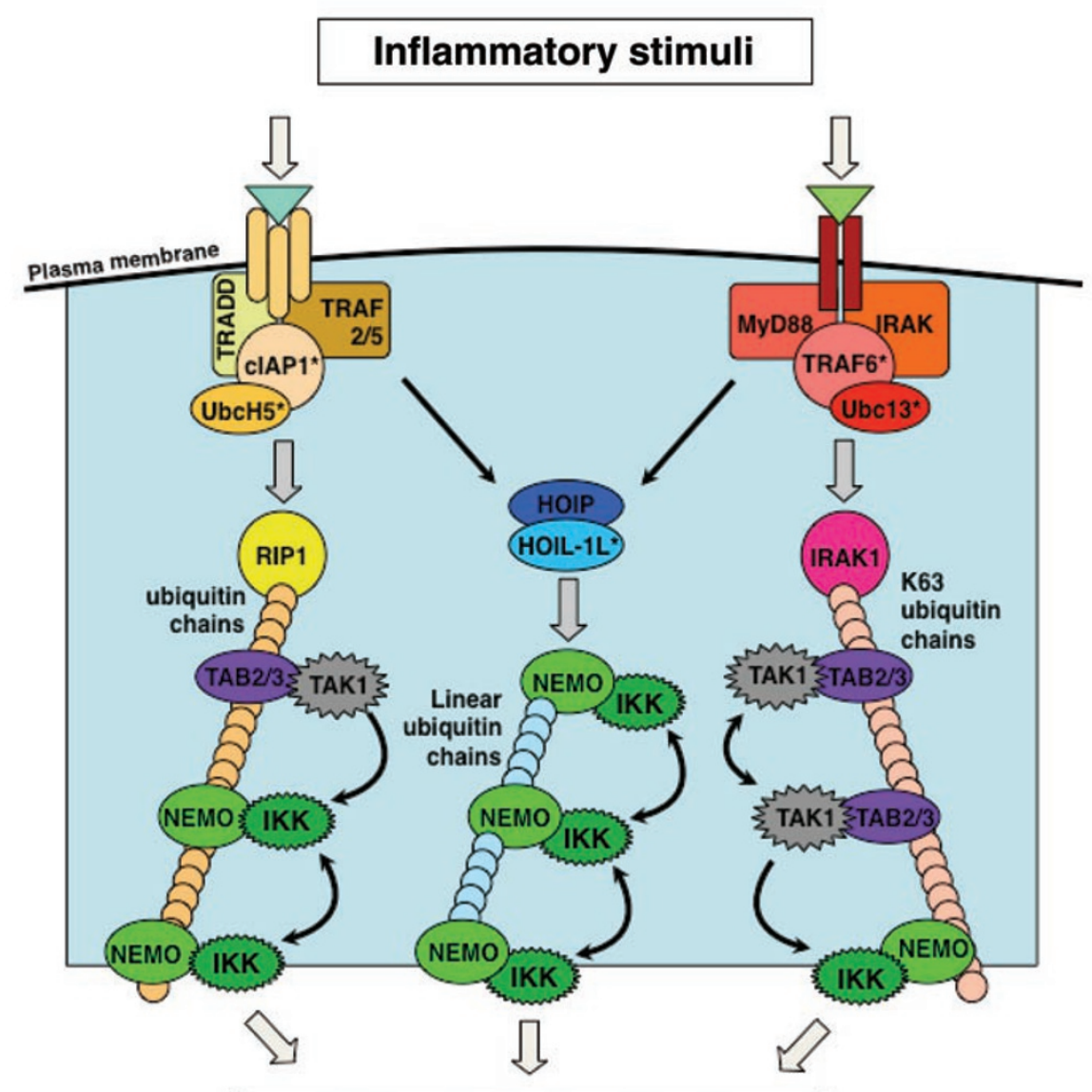

IKK and NFKB activation

Figure 3 Mechanisms of canonical IKK activation. Several distinct pathways of canonical IKK activation have been described: LEFT, upon TNFR engagement, receptor-associated proteins such as TRADD and TRAF2/5 recruit the E2/E3 ligase complex consisting of clAP1 and $\mathrm{UbcH} 5$. clAP1/UbcH5 subsequently conjugate ubiquitin chains of various types of linkages to RIP1, which allows for TAK1 complex and IKK binding. The binding of Ub by the TAK1 complex activates TAK1 and allows it to activate IKK; in addition, Ub binding by the IKK complex induces IKK activation, allowing IKK to trans-autophosphorylate. Center, upon ligand binding of the TNFR, the ubiquitin ligase complex consisting of HOIP and HOIL-1L, known as LUBAC, is recruited by TRADD, TRAF2 and cIAP1. LUBAC conjugates linear-linked ubiquitin to NEMO in the IKK complex, resulting in IKK activation via trans-autophosphorylation. Right, when members of the TLR/IL-1R family are engaged, receptor-associated proteins Myd88 and IRAK recruit the E2/E3 ligase complex consisting of TRAF6 and Ubc13, which conjugates K63-linked ubiquitin chains to IRAK1. The TAK1 complex binds these K63 Ub chains, leading to TAK1 activation, presumably by transautophosphorylation. TAK1 subsequently activates nearby IKK. How these and possibly other mechanisms that result in canonical IKK activation combine to transduce signaling from different receptors remains an active area of investigation.

Disrupting TNF signaling prevents this lethality, and generation of the rela ${ }^{-/}$tnfr $1^{-/-}$or rela ${ }^{-/}$tnf $f^{-/}$genotype allows for these mice to survive embryogenesis so that the absence of RelA can be studied [24, 25]. The rela ${ }^{-/}$tnfr $1^{-/}$genotype results in defects in the immune system, confirming the requirement of RelA for a functioning immune and inflammatory response in cells. By delaying embryonic death (compare $\mathrm{rela}^{-/}, \mathrm{crel}^{{ }_{-}} \mathrm{rela}^{-/}$), cRel partially compensates for the loss of RelA in rela ${ }^{-/-}$ mice, suggesting that cRel and RelA have overlapping functions in mediating survival signals in fetal liver cells [26]. As $\mathrm{crel}^{-} \mathrm{rela}^{-/}$immune system shows more severe phenotypes than either of the single gene knockouts [27], it also appears that these two effectors have overlapping functions in the survival of lymphocyte precursors.

Whereas the importance of the RelA- and cRel-containing $\mathrm{NF} \kappa \mathrm{B}$ dimers in the immune and inflammatory response demonstrated by genetic ablation studies was anticipated based on prior biochemical studies in various cell types, the survival defect in rela ${ }^{-/}$genotypes and 


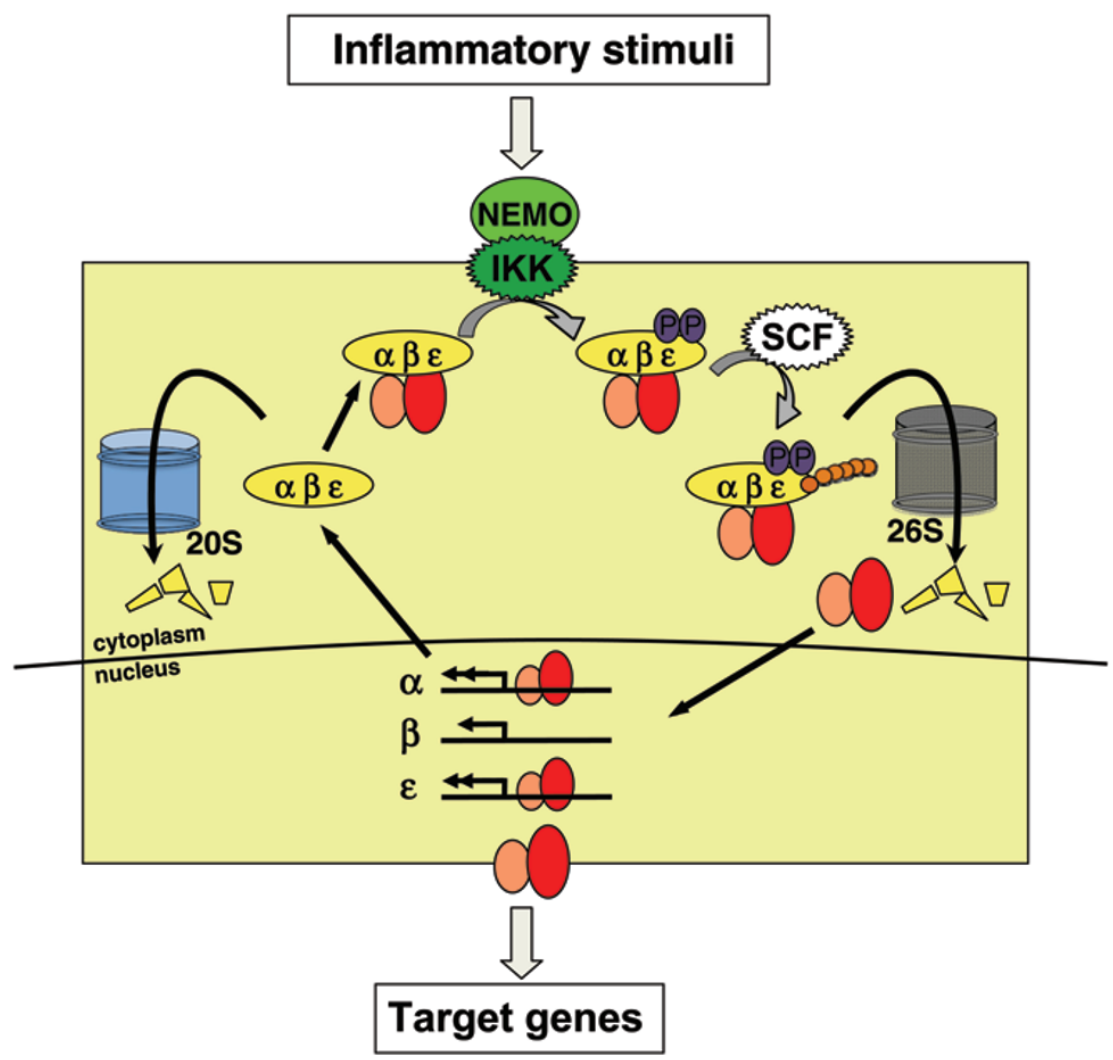

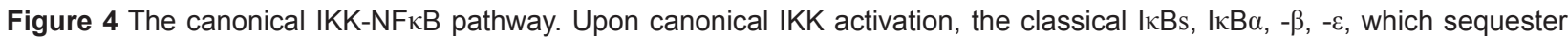
$\mathrm{NF} \kappa \mathrm{B}$ to the cytoplasm in a stoichiometric manner, are phosphorylated on specific N-terminal residues that function as docking sites for the E3 ubiquitin ligase complex SCF/ $\beta$ TRCP. Ubiquitinated $1 \kappa B \alpha$ is degraded by the $26 S$ proteasome, allowing for translocation of $\mathrm{NF} \kappa \mathrm{B}$ into the nucleus. Nuclear $\mathrm{NF} \kappa \mathrm{B}$ activity induces the expression of $I_{\kappa} \mathrm{B} \alpha$ and $I_{\kappa} \mathrm{B} \varepsilon$, providing for negative feedback. Free IкB proteins are rapidly degraded in a ubiquitin-independent manner by the $20 \mathrm{~S}$ proteasome, presumably in conjunction with alternate proteasome targeting or activating proteins.

the role of $\mathrm{NF \kappa B}$ in regulating apoptosis and possibly other forms of cell death - though now well established - was initially surprising. Studies have shown that RelA is crucial in preventing TNF-mediated apoptosis in many different cell types, including macrophages, hepatocytes and $T$ cells $[23,28,29]$. An interesting question is how critical the stimulus-responsive activation of the canonical pathway is for this survival function of $\mathrm{NF \kappa B}$ or whether it is mediated by some other regulatory mechanism that controls RelA activity. The fact that deficiency of TBK1, which does not participate in the canonical pathway but may mediate phosphorylation of RelA, also results in massive fetal liver apoptosis [30] may indicate that the latter is the case.

It remains surprisingly unclear whether specificity between $\mathrm{NF} \kappa \mathrm{B}$ dimers and DNA sequences plays an important role in NFkB-dependent gene activation. In macrophages, IL12 p40 was reported to specifically require $\mathrm{cRel}$ for its LPS-induced gene expression [31].
A systematic genetic analysis of the RelA-containing $\mathrm{NF} \kappa \mathrm{B}$ dimers showed that some NFKB target genes had different activation requirements with regard to specific $\mathrm{NF} \kappa \mathrm{B}$ proteins [32]. Further, swapping promoter-binding

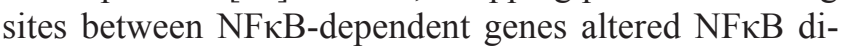
mer specificity, suggesting that single nucleotides within the $\kappa \mathrm{B}$ site may be determinants for dimer specificity [33]. RelA/cRel chimeras identified amino acids within the DNA-binding domain as mediating the specificity of cRel for IL12 transcriptional control [34]. Interestingly, there are indications that dimer specificity may not be mediated by large affinity differences in dimer- $\kappa \mathrm{B}$ site interactions, but may be mediated by alternate conformations of dimers triggered by alternate $\mathrm{\kappa B}$ site sequences $[33,35]$. According to this model, DNA-triggered allostery of the NFKB dimer may be "read" by co-activators or transcriptional activators, such as Bcl3, CBP, or IRF3, interacting with the NFKB dimer.

Physiologically, dimer specificity is suggested by dis- 
tinct phenotypes of knockouts; however, phenotypic differences may be due to distinct tissue-specific expression of the proteins (e.g., cRel is abundant in the lymphoid system) or pathway-specific activation of dimers (e.g., RelA/cRel vs RelB). Thus, the extent of NFkB dimer specificity in regulating $\mathrm{NF \kappa B}$ target genes and the underlying mechanisms for such specificity remain to be addressed. Contemporary tools of genome-wide expression and location studies, and bioinformatic analysis, should prove useful in this endeavor.

\section{Kinetic control of the canonical pathway}

The activation of the canonical pathway results in expression of inflammatory and immune response genes. These signals must be transient and properly controlled, as prolonged $\mathrm{NF \kappa B}$ activation can lead to aberrant gene expression, and the misregulation of $\mathrm{NF} \kappa \mathrm{B}$ activation has been implicated in pathologies including chronic inflammation and cancer. Hence, it is not surprising that numerous mechanisms have evolved to provide for postinduction attenuation or termination of signaling (Figure 5).

The biological importance of the I $\kappa$ Bs as negative feedback regulators in NFKB signaling has been established. Both $\mathrm{I} \kappa \mathrm{B} \alpha$ and $\mathrm{I} \kappa \mathrm{B} \varepsilon$ are inducibly expressed and function as negative feedback regulators of $\mathrm{NF \kappa B}$. I $\mathrm{KB} \alpha$ knockouts result in lethality 7-10 days after birth due to hyperinflammation [36]. In addition, mice with mutated $\kappa \mathrm{B}$ enhancers of the I $\mathrm{B} \alpha \alpha$ promoter display shortened life span (13-15 months), hypersensitivity to septic shock and abnormal T-cell development/activation [37]. IкB $\varepsilon$ knockout mice are not lethal, but result in the increased expression of cytokines [38]. Mice deficient in both $\mathrm{I} \kappa \mathrm{B} \alpha$ and $\mathrm{I} \kappa \mathrm{B} \varepsilon$ result in neonatal lethality and almost complete absence of both $\mathrm{B}$ and $\mathrm{T}$ cells and reduced NK cell numbers [39], indicating overlapping functions of these two I $\kappa$ Bs that may therefore be considered fail-safe duplicates. Indeed, $\mathrm{I} \kappa \mathrm{B} \varepsilon$ is upregulated in resting $\mathrm{I} \kappa \mathrm{B} \alpha-$ deficient cells. This upregulation is reversible upon IкB $\alpha$ reconstitution in the deficient cells [40].

Interestingly, it was recently shown that spontaneous dissociation of NFkB RelA:p50 from DNA can be enhanced by $\mathrm{I} \kappa \mathrm{B} \alpha$, but not by IкB $\beta[41]$. Kinetic enhance-

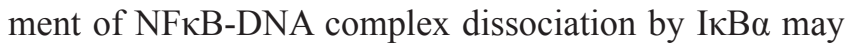
facilitate negative feedback-mediated NFKB post-induction repression, particularly in the transcriptional deactivation of genes that have multiple $\kappa \mathrm{B}$ sites. However, further studies are required to test this prediction.

An additional I $\kappa B$ negative feedback loop was recently characterized. Newly synthesized $n f k b 2$ protein p100 may form multimers in the absence of sufficient IKK1 signaling that catalyzes its degradation or process- ing into $\mathrm{p} 52$. These multimers may exhibit I $\mathrm{B}$ activity when a p100 ARD traps RelA:p50 dimers in trans. Because p100 expression is inducible by RelA:p50, this forms a negative feedback loop that has slow kinetics, yet is not degraded when canonical IKK activity persists. Computational simulations-directed experimental studies revealed that $\mathrm{I} \kappa \mathrm{B} \delta$ forms a negative feedback loop to regulate RelA:p50 activity in a stimulus-specific manner, such that it is effective to LPS but not to TNF [3]. Indeed, the work revealed that I $\mathrm{I} B \alpha$ provides effective negative feedback only to cytokine stimuli that produce transient canonical IKK activity. Perinatal lethality observed in I $\mathrm{BB} \alpha$-deficient mice could be rescued when the inducing stimulus TNF was ablated.

I $\mathrm{Bs}$ function as stoichiometric inhibitors that quickly sequester NFKB in the cytoplasm. A20, on the other hand, inhibits signaling upstream of IKK via its enzymatic function as a protease of signaling-associated K63linked ubiquitin chains [42]. While both $\mathrm{A} 20$ and $\mathrm{I} \kappa \mathrm{B} \alpha$ are inducible negative regulators, only I $\mathrm{B} \alpha$ functions as a dynamic negative feedback regulator [43]. Instead, the evidence indicates that A20 may be thought of as a tunable rheostat that determines IKK and NFאB responsiveness to subsaturating stimuli.

Degradation of promoter-bound RelA dimers may also be a stimulus-induced post-induction attenuation mechanism. RelA degradation was proposed to be essential for the transient activity of NFKB RelA dimers [44]. It has also been shown that genes activated by RelA dimers can be negatively regulated by the E3 ligase PIAS1, a member of the protein inhibitor of activated STAT (PIAS) family [45]. Pias $1^{-/}$mice showed significantly elevated RelA binding to $\kappa \mathrm{B}$ sites in genes that also showed hyper-expression [46]. A second line of research provided evidence that promoter-bound RelA and cRel can be phosphorylated by IKK activity thereby catalyzing their degradation [47]. This would constitute a negative feed-forward mechanism, a potential timing device that ensures that the released $\mathrm{NF \kappa B}$ activity is transient. While IKK results in the phosphorylation of IkBs and the nuclear translocation and activation of $\mathrm{NF \kappa B}$, it may also limit the duration of $\mathrm{NF \kappa B}$ activity through the direct phosphorylation of RelA and cRel that targets them to the ubiquitin proteasome pathway.

Not only does negative feedback limit the duration of stimulus-induced NFKB activity and the magnitude of the gene expression response, it may also mediate the transduction of stimulus-specific information via a "temporal signaling code" that determines which of the many possible target genes are activated in response to a specific stimulus. I $\mathrm{B} B \alpha$ deficiency for example, which alters the TNF-induced dynamic controls, results in inappropriate 


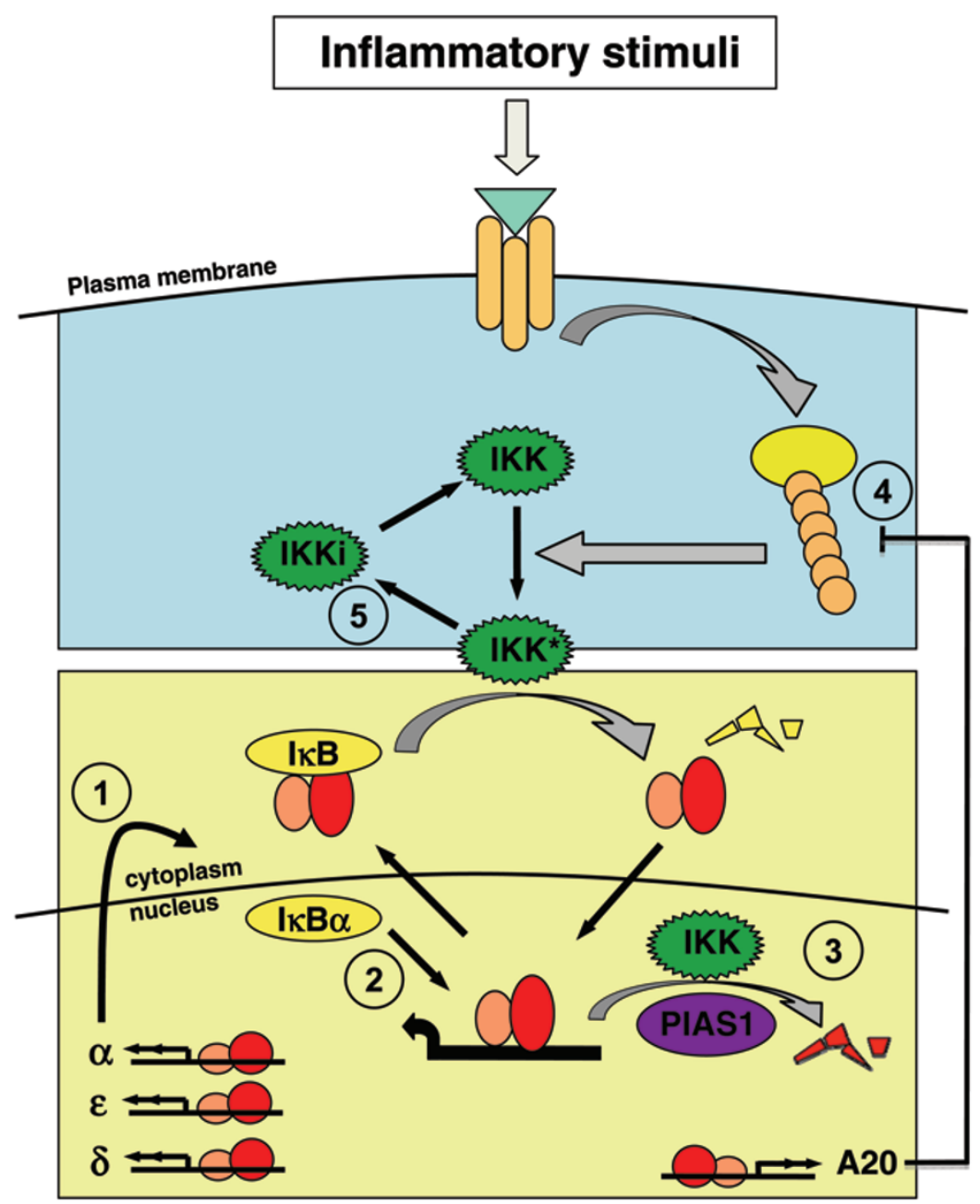

Figure 5 Mechanisms of canonical pathway attenuation. The best characterized attenuation mechanism is negative feedback synthesis of $I_{\kappa} B$ proteins (1). I $\mathrm{KB}_{\alpha}$ was recently shown to have the ability to enhance the dissociation rate of NF $\kappa B$ from DNA, which may facilitate its negative feedback control function (2). In addition, DNA-bound RelA NFKB, when phosphorylated on S536 by nuclear IKK complexes, was shown to be subjected to ubiquitination by the E3 ligase PIAS1, which targets NFKB to degradation (3). The ubiquitin protease A20, a highly inducible NFאB target gene, attenuates the IKK activation pathway by counteracting E3 ligases involved in the formation of ubiquitin chains that are critical signaling scaffolds (4). In addition, canonical IKK was proposed to undergo autophosphorylation that results in an inactivated kinase (5); a recycling step is necessary to return IKK back to the activatable state.

gene expression [48]. Further, IкB $\varepsilon$ appears to dampen I $\kappa \mathrm{B} \alpha$-mediated $\mathrm{NF} \kappa \mathrm{B}$ oscillations, because its mRNA induction is delayed to occur in anti-phase with that of $\mathrm{I} \kappa \mathrm{B} \alpha[49]$. In addition, newly synthesized $\mathrm{I} \kappa \mathrm{B} \delta$ forms a negative feedback loop to regulate RelA:p50 activity in a stimulus-specific manner, as described above [3]. Singlecell studies with fluorescent fusion proteins of RelA and I $\mathrm{B} \alpha$ have drawn attention to the potential for oscillatory control of NFKB, suggesting that frequency of successive $\mathrm{NF} \kappa \mathrm{B}$ peaks is a critical feature of the temporal code $[50,51]$. However, it remains unclear whether inap- propriate expression of the fusion protein may impact the physiological relevance of these observations and whether frequency of $\mathrm{NF \kappa B}$ peaks is in fact a function of the stimulus. An alternate view may be that cell-to-cell variability of periodic $\mathrm{NF} \kappa \mathrm{B}$ activities (potentially the result of transcriptional bursting of the short-lived I $\kappa \mathrm{B} \alpha$ inhibitor) may impart functional robustness at the organ or tissue level [52]. The temporal code may thus be better described as amplitude modulated (AM) rather than frequency modulated (FM). However, the information carrier of AM signals may involve periodic or irregularly 
spaced activity peaks.

Stimulus-specific temporal control of NFkB is a result of the stimulus-specific temporal control of the canonical IKK activity [53]. It is interesting to note that TNFinduced IKK activity rises rapidly and is rapidly attenuated. Though the negative regulator A20 plays some role in determining this temporal profile, it remains unknown what the mechanisms are, which ensure that IKK activity undergoes rapid post-induction repression. Early studies identified C-terminal residues on the IKK2 protein that dampen its kinase activity, suggesting a cyclical control cycle [10]. However, this model has not been substantiated. In contrast, LPS-induced IKK activity shows a mode of slower activation but of longer duration. Interestingly, the longer duration is in part due to co-opting the TNFR pathway at late time points through the expression of TNF at early time points $[53,54]$.

Stimulus-specific temporal profiles of IKK and NFKB are correlated with the expression of stimulus-specific genes. Although inactivation of the TNF autocrine loop provided a means to manipulate the LPS-specific IKK temporal profiles [53], this intervention may also affect a parallel pathway. Thus, whether the stimulus-specific temporal profiles of $\mathrm{NF} \kappa \mathrm{B}$ activity encode information about the stimulus that is critical for stimulus-specific gene expression remains to be tested rigorously. Furthermore, it remains unknown how promoters of activated genes, or associated gene regulatory networks, distinguish between different temporal profiles. Understanding the mechanisms by which the temporal activity profile is decoded by target genes and elucidating what features of the temporal profile of NFKB activity carry stimulusspecific information remain the pressing questions in the field [55].

Finally, studies of the cellular steady state have shown that a short half-life of free classical I $\kappa$ B proteins $(<10$ min) necessitates a surprisingly high constitutive synthesis rate [40]. Subsequent work showed that the short half-life of free I $\mathrm{I} \mathrm{B} \alpha$ is mediated by the ubiquitin-independent proteasome pathway and is likely due to incompletely folded regions of C-terminal ankyrin repeats that have evolved away from the consensus [56, 57]. Further studies showed that the high apparently futile flux of $\mathrm{I} \kappa \mathrm{B}$ metabolism ensures relative resistance to metabolic and ribotoxic stress agents, such as UV and UPR, ensuring that the NFKB signaling module is dedicated to sensors of the extracellular environments such as TLR and cytokine receptors that produce significant changes in canonical IKK activity [58]. Thus, the distinct degradation pathways between the free and bound I $\kappa$ Bs result in highly dynamic homeostatic control of the NFKB signaling module, which imparts functional robustness to this signaling system.

\section{The non-canonical pathway}

Activation of the non-canonical NFkB pathway (Figure 6) is mediated through a NEMO-independent IKK1 kinase complex [59]. Recent reports indicated that the regulated assembly of the upstream signaling complex that involves cellular inhibitor of apoptosis (cIAP1 and cIAP2), TRAF2 and TRAF3, and NIK is crucial for the activation of this pathway. Upon receptor engagement, TRAF2-dependent recruitment of cIAP1 and cIAP2 results in activation of cIAPs and K63-linked ubiquitination by TRAF2. TRAF3 serves as an adaptor molecule that allows for the assembly of a complex involving NIK, TRAF2 and activated cIAPs, which causes TRAF3 itself to be modified by K48-linked ubiquitination by cIAPs [60, 61]. As NIK protein expression is regulated by TRAF3, signal-induced proteosomal degradation of TRAF3 leads to accumulation of NIK protein and activation of the downstream pathway $[62,63]$. Increase in NIK protein results in phosphorylation of p100 at Ser866 and Ser870, and activation of IKK1 [64, 65]. Activated IKK1-containing kinase complex further phosphorylates p100 at Ser99, Ser108, Ser115, Ser123 and Ser872. Phosphorylation of these residues provides a signal for p100 to be recognized by the SCF/BTRCP ubiquitin ligase complex, and this results in partial degradation of the C-terminal ARD of $\mathrm{p} 100$ by the $26 \mathrm{~S}$ proteosome [66]. Two mechanisms of $N F \kappa B$ activation ensue: first I $\mathrm{I} B \delta$ within the p100-containing I $\kappa$ Bsome is inactivated through degradation of the C-terminal ARD of p100, leading to the release of associated RelB:p50 and RelA:p50 dimers. Second, co-translational processing of p100 that requires de novo protein synthesis leads to nuclear translocation of the major RelB-containing dimer, RelB:p52, and RelA:p52 as a minor species $[1,67,68]$.

The sequence of molecular events that result in stimulus-induced RelB:p52 dimers remains surprisingly poorly understood. RelB associates with p100 through multiple protein-protein contacts. This multidomain interaction results in protein co-stabilization, as $n f k b 2^{-/}$cells showed reduced level of RelB protein and relb ${ }^{-/}$cells have decreased amounts of p100 protein [69, 70]. Counterintuitively, this interaction also inhibits $\mathrm{p} 100$ processing and RelB:p52 formation, suggesting that RelB:p52 dimer formation may occur after $\mathrm{p} 100$ processing, though it may involve alternate, transient interactions with $\mathrm{p} 100$.

Unlike the canonical NFKB pathway, there are few reports for negative feedback control of the non-canonical pathway. NFkB-inducible expression of TRAF3, which plays a negative role in non-canonical signaling, may im- 


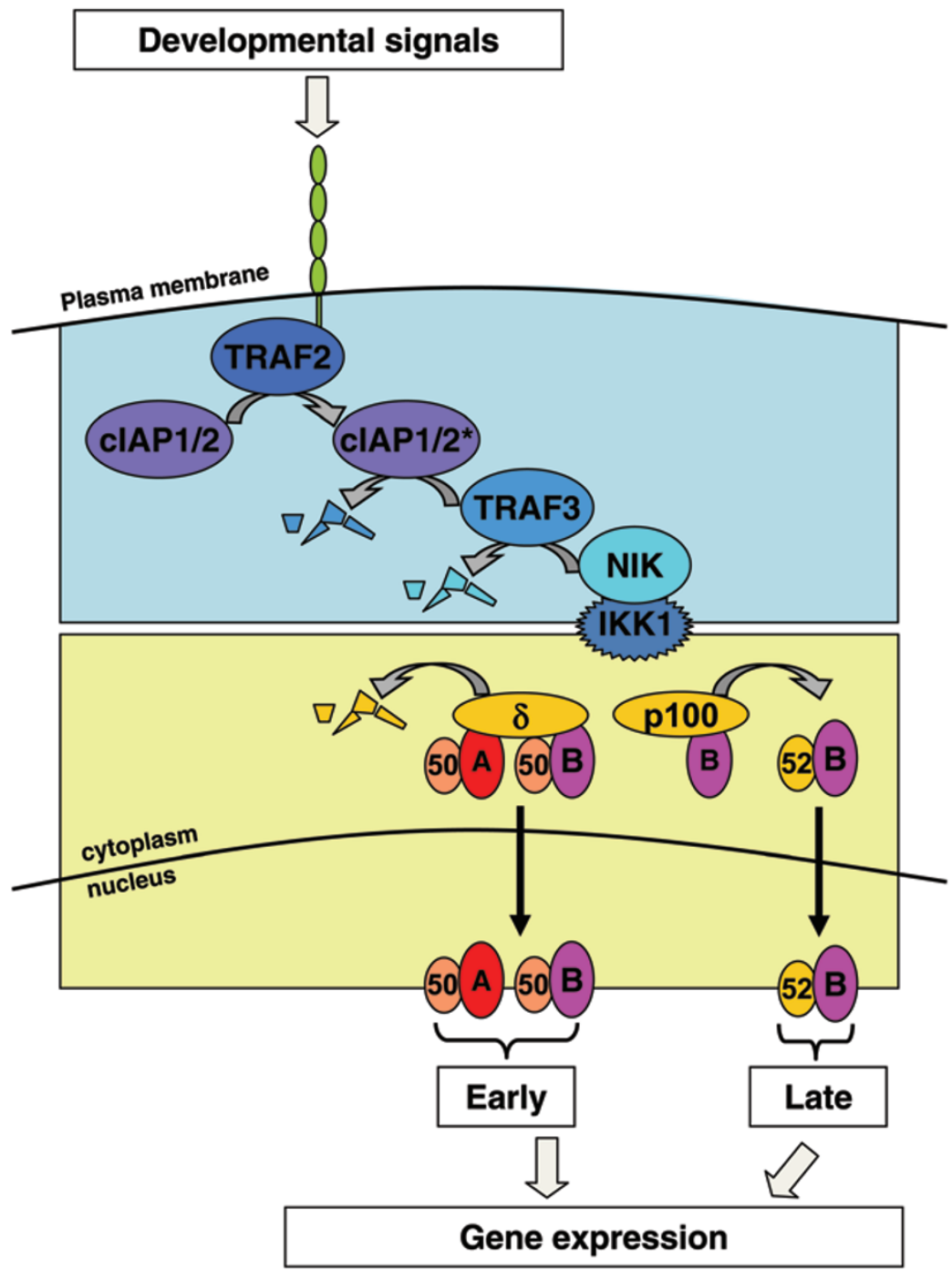

Figure 6 The non-canonical NFאB pathway. Receptor engagement leads to recruitment and activation of clAP1/2 mediated by TRAF2 resulting in the degradation of TRAF3. Decreased levels of TRAF3 stabilize NIK, which in turn activates IKK1 ac-

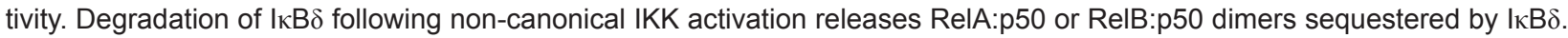
Processing of newly synthesized p100 also occurs and generates RelB:p52 complex, whose levels slowly build up to provide sustained activity of the RelB:p52 dimer. Translocation of NFאB dimers to the nucleus activates gene expression program.

pede RelB activation by degrading NIK. Phosphorylation of NIK on Ser809, Ser812 and Ser815 by IKK1 destabilizes NIK and provides a way to fine-tune non-canonical signaling [71]. MicroRNAs - miR-223, miR-15a, miR16 - that have been implicated in targeting IKK1 during macrophage differentiation may modulate the strength of non-canonical signaling, if upregulated upon stimulation [72]. In primary thymocytes, phosphorylation of RelB stimulated by TPA/ionomysin leading to degradation of RelB may serve as a mechanism to control signalinducible protein turnover [73]. In general, however, dynamic control of RelB activity has not been observed.
It seems unlikely that there is a mechanism analogous to IкB-mediated removal of RelA:p50 from $\kappa \mathrm{B}$ sites or the nucleus that is applicable to nuclear RelB-containing dimers.

The non-canonical pathway is activated by the engagement of a subset of tumor necrosis factor receptors that are involved in development. Given roles of the non-canonical pathway in developmental processes that require sustained signaling, its kinetics involve a slow build-up of activity and long-lasting activity, as opposed to the acute activation of RelA-containing dimers induced by inflammatory stimuli. Stimuli that have been reported to activate non-canonical signaling include 
lymphotoxin $\beta$ (LT $\beta$ ), B cells activating factor (BAFF), $\mathrm{CD} 40$ ligand and receptor activator of $\mathrm{NF} \kappa \mathrm{B}$ ligand (RANKL), etc. Studies using genetically deficient cells or mice have shown the essential role of non-canonical $\mathrm{NF} \kappa \mathrm{B}$ pathway in various biological processes. Mice deficient in components of non-canonical pathway $-\mathrm{relb}^{--}$, $n f k b 2^{-/}, n i k^{--\alpha}$ and NIK ${ }^{\text {aly/aly }}$ mice that bear a point mutation on nik alleles - showed defective development of lymph nodes and Peyer's Patch [74-78]. p100 and RelB are required for maintaining proper splenic architecture as $n f k b 2^{--}$and $r e l b^{--}$mice lack germinal centers and follicular dendritic cells network [79-81]. Reduced number of marginal zone B cells was observed in both $n f k b 2^{-/-}$ and $\mathrm{relb}^{-/-}$, indicating the importance of non-canonical signaling in B-cell development [81]. Involvement of the non-canonical pathway in mammary gland development has also been implicated. IKK $1^{\mathrm{AA}}$ mice that do not have functional IKK1 kinase activity are defective in lactation during pregnancy [82]. RelB:p52 activation was proposed to rescue the delay in the early mammary gland development observed in transgenic mice overexpressing the I $\mathrm{B} \alpha$ super-repressor [83]. Defective osteoclastogenesis observed in $n i k^{-/}$mice can be restored by overexpressing RelB, but not RelA, indicating a specific function of RelB in osteoclast differentiation [84]. Further, specific expression of relb transcripts was found in antigen-presenting cells, and requirement of RelB for $\mathrm{CD} 4{ }^{+} \mathrm{CD} 8 \alpha^{-}$dendritic cell development was reported [85-87]. Even though the physiological function of RelB in DC and MZB cell development has been established, the mechanistic aspects of its regulation and the downstream target gene expression programs have not been revealed.

Supporting a role of the non-canonical pathway in secondary lymphoid organ development, splenocytes from IKK $1^{\mathrm{AA}}$ knock-in mice injected with LT $\beta \mathrm{R}$ agonist showed defective expression of chemokine genes, including secondary lymphoid tissue chemokine (SLC), EBI1 ligand chemokine (ELC), B lymphoblastoid cell chemokine (BLC), and stromal cell-derived factor $1 \alpha$ (SDF-1 $\alpha$ ) [88]. Dependence on RelB for expression of these genes was further established by comparing molecular events downstream of LT $\beta$ R signaling in wt and $\mathrm{relb}^{-/}$MEF [70]. Selective recruitment of RelB to the promoter region of these genes and in vitro binding assays between $\mathrm{NF \kappa B}$ dimeric complexes and DNA probes suggested that RelB:p52 recognizes specific $\kappa \mathrm{B}$-binding sites that are different from those bound by RelA:p50 [89]. However, genome-wide gene expression analysis derived from LT $\beta$ R-stimulated MEF revealed that the majority of the induced genes require both RelA- and RelB-containing dimers [90]. RelB:p52 and RelA:p50 complexes derived from eukaryotic cells showed similar ability to bind to consensus binding sites [91]. Further, B cells with constitutive IKK2 activity (IK$\mathrm{K} 2 \mathrm{ca}$ ) show rescue of the developmental block observed in BAFF-R-deficient B cells [92]. It suggests that nuclear accumulation of RelA, cRel and p50 in IKK2ca+ B cells can compensate for the loss of RelB:p52 activation in $\mathrm{B}$ cells deficient in BAFF-R signaling. Interestingly, analysis of crystal structure of RelB-containing dimers suggested that RelB may recognize a broader range of $\kappa B$ sequences than other dimers $[93,94]$. In sum, studies performed so far have not been able to reach a definite conclusion if different NFkB dimers activated by the non-canonical pathway have specific or overlapping gene activation functions.

\section{Crosstalk between canonical and non-canonical pathways}

Activation of the canonical NFאB pathway is generally associated with inflammatory exposure, whereas activation of the non-canonical pathway is mostly related to developmental cues. These two pathways were first thought to transduce signals independently and have separate physiological functions [95]. Interestingly, several studies have provided evidence that inter-connections between these two pathways exist.

\section{Control of RelA:p50 by non-canonical signals}

In early overexpression studies, RelA was reported to be associated with the C-terminal portion of p100 [96]. Mice expressing a mutant form of p100 that does not allow for processing show defective activation of RelAcontaining dimers, impaired development of secondary lymphoid organs and B cells, and impaired osteoclastogenesis [97]. Cytosolic accumulation of p100 in $\mathrm{nik}^{-/}$ osteoclast precursors leads to enhanced association of RelA with p100 and defective RANKL-induced osteoclastogenesis [98]. Sequestration of RelA:p50 by p100 mediates a immunosuppressive phenotype observed in $n i k^{-/}$mice through regulating the activation of naïve $\mathrm{T}$ cells [99]. Developmental LT $\beta$ R signaling disrupts the I $\kappa B \delta$ inhibitory complex, which results in the release of canonical effector RelA:p50 into the nucleus. Further, increased amount of RelA associated with I $\mathrm{I} B \delta$ in TNFprimed cells leads to enhanced LT $\beta R$-induced inflammatory gene expression [1]. These studies indicated that $\mathrm{I} \kappa \mathrm{B} \delta$, capable of inhibiting RelA and responsive to non-canonical stimuli, serves as a mediator of crosstalk between canonical and non-canonical NFKB signaling. Moreover, regulation of $\mathrm{I} \kappa \mathrm{B} \delta$ may thus modulate $\mathrm{NF} \kappa \mathrm{B} /$ RelA activity by balancing canonical and non-canonical 
signaling, when cells are physiologically exposed to multiple stimuli.

Given this emerging understanding of NFKB control (Figure 7A), chronic inflammatory mediators should not give rise to chronically elevated $\mathrm{NF} \kappa \mathrm{B}$ activation given the irreversible feedback control mediated by $\mathrm{I} \kappa \mathrm{B} \delta$. However, in a microenvironment where inflammatory exposure is accompanied by developmental factors that promote I $\kappa \delta \delta$ degradation, prolonged RelA:p50 activity may be the outcome. Tonic developmental signals, which are not considered detrimental, may exacerbate chronic inflammation when I $\mathrm{K} B \delta$ is constitutively degraded. Indeed, several studies have found that B- and T-cell leukemias/lymphomas have mutations in $n f k b 2$ gene that result in the removal of its inhibitory domain $[100,101]$. Elevated expression of NIK and p100 processing, a hallmark of non-canonical pathway activation, were found in multiple myeloma cell lines and primary MM patients' samples $[102,103]$. However, it should be noted that RelA-containing dimer can be activated through a NIKIKK2 axis when NIK protein accumulates in cells $[60,104]$. Clarifying the contribution of non-canonical pathway activation in the misregulation of canonical $\mathrm{NF} \kappa \mathrm{B}$ effectors will affect treatment strategies for inflammatory diseases and cancers.

\section{RelA:p50 control of non-canonical signaling}

Another layer of interdependency between the canonical and non-canonical NFKB pathways is based on transcriptional control (Figure 7B). Early studies showed that the promoter regions of relb and $n f k b 2$ genes contain $\kappa \mathrm{B}$-binding sites and transcriptional regulation of these two genes is dependent on RelA $[105,106]$. LT $\beta R$ signaling was shown to activate RelA:p50 followed by RelB:p52 via two distinct pathways [107]. Activation of RelB-containing dimers by LT $\beta$ R signaling is deficient in rela $^{-/}$MEF, suggesting a requirement of RelA for transcription of relb and $n f k b 2$. Reconstitution of relb or constitutive form of IKK2 into rela ${ }^{-/-}$MEF restored LT $\beta R$-induced RelB activation. However, overexpression of p100 in rela ${ }^{-/}$MEF failed to restore LT $\beta$ R-induced RelB activity [70]. These genetic/biochemical analyses indicated that homeostatic relb transcription driven by basal RelA activity, rather than p100 synthesis induced by RelA activation, is the main determinant of noncanonical pathway responses. Interestingly, mice lacking RelA (TNFR1-deficiency background) mirrored the phenotypes observed in mice deficient in components of the non-canonical pathway. RelA-deficient mice showed an absence of lymph nodes, Peyer's Patch and disorganized splenic microarchitecture [108], supporting the cross-regulatory mechanism between canonical and non-canonical pathways provided by ex vivo studies. The requirement of canonical NFKB activity for providing non-canonical $\mathrm{NF} \kappa \mathrm{B}$ activation in lymph nodes formation represents a physiologically relevant interdependency between these
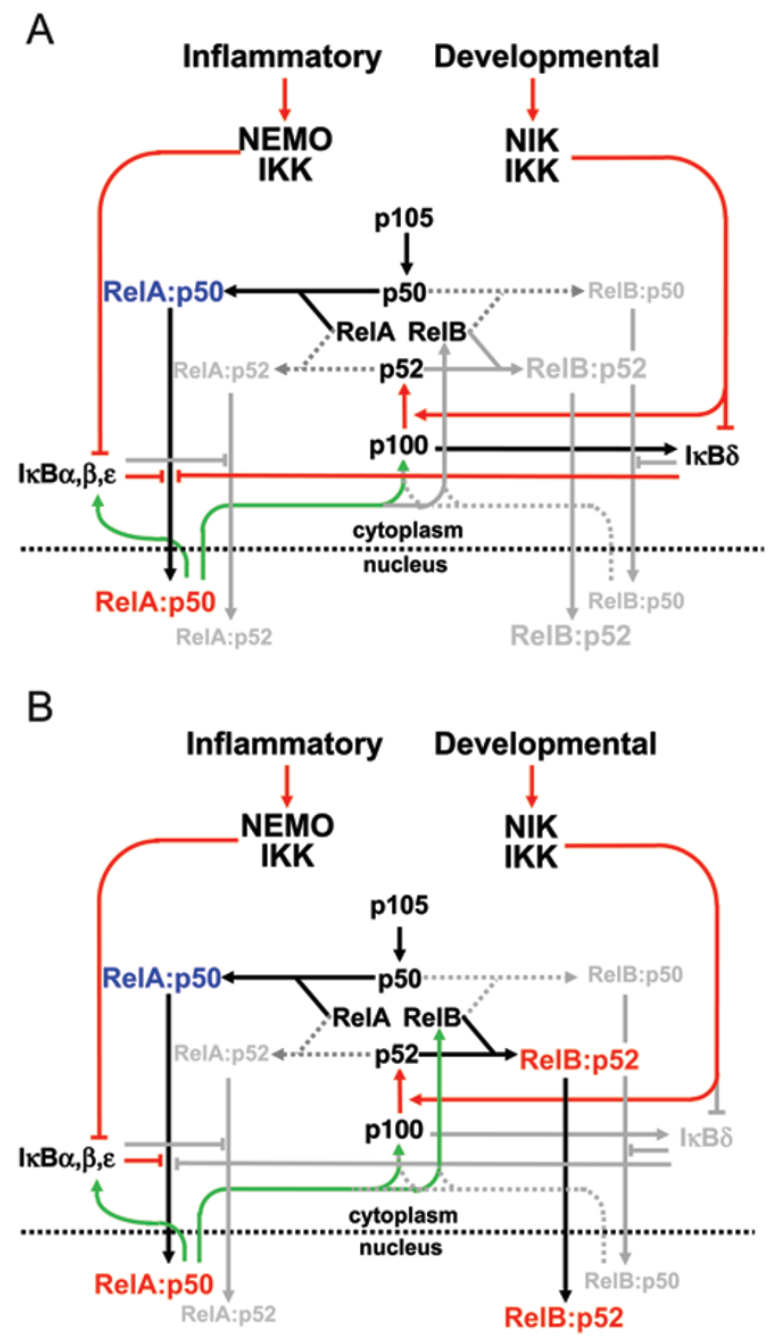

Figure 7 Wiring diagrams of the NFאB signaling system to chart crosstalk between canonical and non-canonical signaling pathways. (A) Non-canonical control of RelA:p50. RelA:p50 is inhibited by not only $I \kappa B \alpha,-\beta,-\varepsilon$, but also $I \kappa B \delta$. Whereas inflammatory canonical signals lead to degradation of $I \kappa B \alpha,-\beta,-\varepsilon$, developmental signals engage the non-canonical pathway to disrupt I $\kappa B \delta$ activity; however, both result in the nuclear translocation of RelA:p50. Interestingly, prior canonical signaling history results in an enhancement of the non-canonical-RelA:p50 axis, due to inducible expression of p100. (B) Canonical control of RelB:p52 activation. Expression of p100 and RelB are dependent on RelA:p50 activity and therefore canonical signals. The amount of basal RelB expression, controlled by constitutive canonical pathway activity, rather than the inducible p100 expression, is the main determinant of the strength of non-canonical signaling. 
two pathways.

\section{Functional overlap between NFKB1 and NFKB2}

$\mathrm{NF} \kappa \mathrm{B}$ gene deletion studies have shown that there is an unexpected interdependence involving functional overlap between $n f k b 1$, which encodes p105/p50, and $n f \kappa b 2$, which encodes $\mathrm{p} 100 / \mathrm{p} 52$. The interplay between these two genes and their importance in both the canonical and non-canonical pathways illustrate the interdependence of the two pathways.

Non-canonical signaling results in prominent RelB:p52 dimer activation that is thought to be important for lymph node organogenesis. Yet, $n f k b 2^{-/-}$mice do not phenocopy $\mathrm{relb}^{-/}$mice in terms of lymph node formation and germinal center organization [109]. Biochemical analysis did confirm that nfkb2-deficient cells show reduced responsiveness to LT $\beta R$ signaling due to lack of $\mathrm{p} 100$, which forms the non-canonical regulator $\mathrm{I} \kappa \mathrm{B} \delta$ and is a necessary precursor for $\mathrm{p} 52$-containing complexes formed upon LT $\beta R$ engagement [70]. However, mutant cells also revealed that the deficiency of the RelB-binding partner p52 results in formation of the RelB:p50 dimer. Thus, constitutive RelB:p50 NFאB activity, which is not controlled by classical $\mathrm{I} \kappa \mathrm{B}$ proteins, I $\mathrm{B} \mathrm{B} \alpha,-\beta$ and $-\varepsilon$, may compensate for the loss of non-canonical pathway-inducible RelB:p52 activity (Figure 8A). These observations provide explanations for the intermediate lymph node phenotypes in $n f k b 2^{-/-}$mice [109].

Canonical activation results in the ubiquitous RelA:p50 dimer. Yet $n f k b 1^{--}$mice show only mild phenotypes in inflammatory regulation, not nearly as severe as $\mathrm{rela}^{--}$ mice [110]. Biochemical analysis of mutant cells showed that loss of p50 results in the formation of RelA:p52, near normal RelA activation in response to inflammatory stimuli, and activation of several RelA target genes [32].

Further studies were prompted by the unexpected finding that $n f \mathrm{kbl}^{-/}$mice also showed lymph node organogenesis defects [109]. Biochemical analysis revealed that the compensatory generation of $\mathrm{p} 52$ via enhanced constitutive p100 processing to provide the binding partner for RelA resulted in reduced p100 levels in $n f k b 1^{-/}$cells, thereby weakening the responsiveness of the non-canonical signaling pathway [70]. Thus, upon stimulation by a non-canonical stimulus such as BAFF or LT $\beta$, less p100 is available for processing to $\mathrm{p} 52$ to form a RelB:p52 dimer complex. Much of the p100 will have already been processed for the formation of the RelA:p52 dimer which is dedicated to canonical signaling (Figure 8B). This weakening of the non-canonical pathway provides a mechanistic explanation for the lymph node organogenesis phenotypes of $n f \kappa b 1^{--}$mice [70].
In sum, p50 and p52 appear to have largely overlapping functions in dimer formation (despite preferences for RelA and RelB, respectively) and target gene activation. However, compensation comes at a price, as the precursors p105 and especially p100 have signaling functions. When their pool is diminished due to compen-

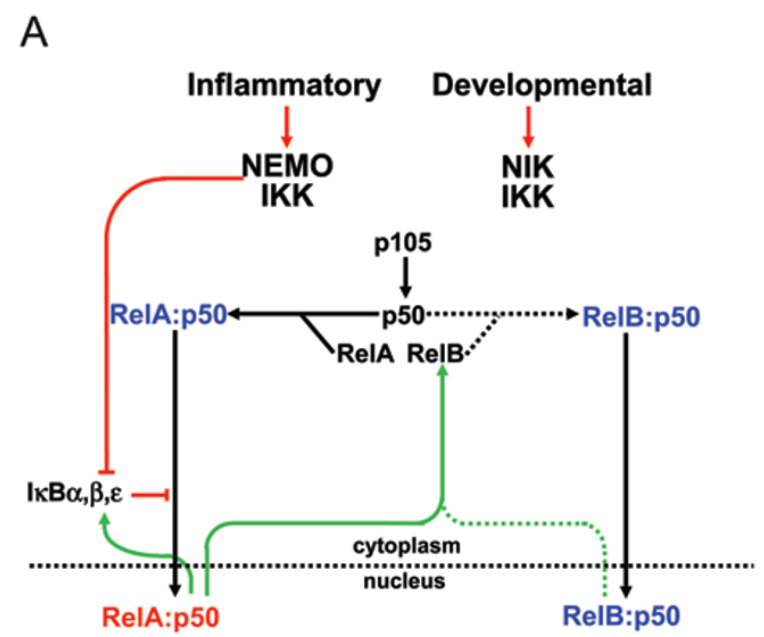

B

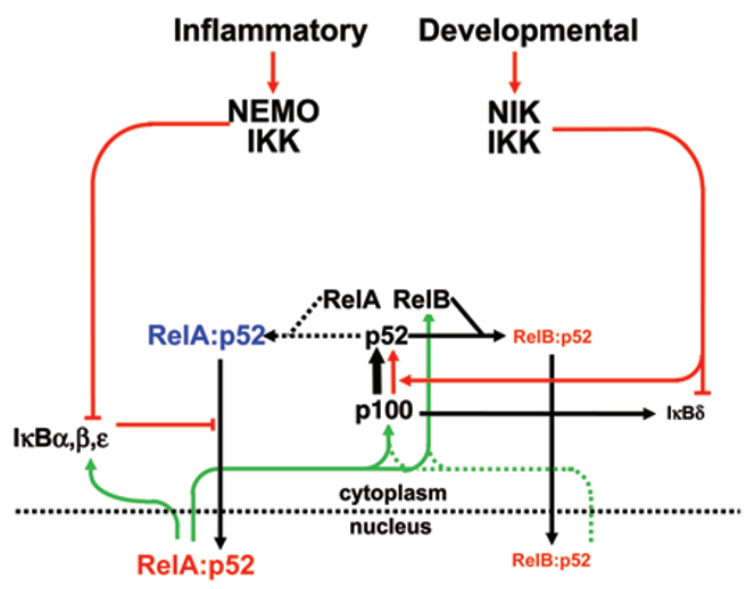

Figure 8 Wiring diagrams of the NFkB signaling system to chart the interdependence and functional overlap of $n f_{\kappa} b 1$ and $n f \kappa b 2$ gene products. (A) The NFאB signaling system in $n f \kappa b 2^{-/-}$cells. Without its normal binding partner p52, RelB will bind p50 to form RelB:p50 dimers, which accumulate in the nucleus. As a result, constitutive RelB:p50 activity compensates for the loss of inducible RelB:p52 activity. (B) The NFKB signaling system in $n f \kappa b 1^{-1-}$ cells. Without its normal binding partner p50, RelA will bind p52 causing an increase in constitutive $\mathrm{p} 100$ processing and thus a depletion of the $1 \kappa B \delta$ and $\mathrm{p} 100$ pool, which is required for RelB:p52 activation. Though the canonical pathway is largely preserved in $n f \kappa b 1^{-/-}$cells, compensation by p52 weakens the non-canonical pathway. 
sation in dimer formation, deficiencies in signaling can occur. Hence, functional overlap between p50 and p52 revealed interdependencies in precursor processing and $n f \kappa b 1$ and $n f \kappa b 2$ gene function.

\section{Conclusions}

The majority of previous $\mathrm{NF \kappa B}$ review articles have focused on the existence of two separate signaling pathways mediated through two biological classes of receptors (inflammatory vs immune cell maturation) that result in activation of two temporally distinct NFKB dimers, namely the RelA/cRel- and RelB-containing dimers. Recent work has indicated that numerous interconnections between canonical and non-canonical NF $\mathrm{NB}$ pathways exist, and these may be crucial in various biological processes. Gene knockout studies also revealed functional overlap and interdependencies between canonical and non-canonical pathways. In sum, we propose the view that $\mathrm{NF} \kappa \mathrm{B}$ signaling mediated by NEMO-dependent or NEMO-independent IKK complexes should be considered within the context of a single regulatory or signaling system. Indeed, biological outcomes are the result of numerous stimuli and intracellular and intercellular signals. A systems view of $\mathrm{NF \kappa B}$ signaling allows one to make sense of otherwise counterintuitive phenomena in physiology and pathology.

Within the NFKB signaling system, stimulus-responsive dynamic regulation of $\mathrm{NF} \kappa \mathrm{B}$ activity is achieved by a network of myriad biochemical reactions that govern

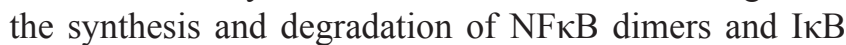
proteins, their interactions with each other, and subcellular localization of the components and complexes. All reactions are potentially regulated by signaling events that are triggered by extracellular stimuli. As reviewed here, in the canonical signaling axis, the focus has been on stimulus-induced degradation and feedback resynthesis of I $\mathrm{KB}$ proteins, though homeostatic control of free $\mathrm{I} \kappa \mathrm{B}$ synthesis and degradation has also been shown to play a critical role. In the non-canonical signaling axis, the focus has been on stimulus-induced generation of the RelB:p52 dimer, though inactivation of the I $\kappa \mathrm{B} \delta$ activity was also shown to be important. However, signaling crosstalk mechanisms demonstrate that biochemical reactions that are not usually associated with a particular signaling axis should also be considered.

A systems understanding of $\mathrm{NF} \kappa \mathrm{B}$ control may seem dauntingly complex: several different IKK kinase complexes, at least $5 \mathrm{I} \kappa \mathrm{Bs}$ and 15 potential NFKB dimeric complexes must be taken into account, as well as their interdependent regulation and temporal control through feedback. Indeed, to understand $\mathrm{NF} \kappa \mathrm{B}$ signaling in such a manner requires the development of mathematical models that represent the biochemical reactions. First of all, such models are useful as repositories of what is known about a regulatory system. Second, when the models are parameterized with rate constants from biophysical or cell biological experiments, they also allow for in silico computational simulations that can be helpful in interpreting experimental data and often directing experimental design by making interesting predictions. Just like model diagrams on paper, such models are a work in progress; however, they are better suited for quantitative and kinetic arguments and thus they can be a useful tool in ongoing research to characterize the functioning of a pathway. Third, when a mathematical model has been extensively validated, it may then in fact be considered a model system, not unlike a model organism or a HeLa or MEF cell line, with which results obtained have value in their own rights in the context of multipronged approaches to discover the molecular basis of human health and disease. Fourth, mathematical model reduction strategies allow one to characterize the regulatory design principles underlying specific regulatory phenomena. As described in this review, an experimentally validated mathematical model of the NFKB signaling system that accounts for the intricate molecular mechanisms pertaining to both canonical and non-canonical signaling will have broad applicability in characterizing the mechanisms underlying cellular regulation in numerous physiological and pathological states.

\section{References}

1 Basak S, Kim H, Kearns JD, et al. A fourth IkappaB protein within the NF-kappaB signaling module. Cell 2007; 128:369-381.

2 Savinova OV, Hoffmann A, Ghosh G. The Nfkb1 and $\mathrm{Nfkb} 2$ proteins p105 and p100 function as the core of highmolecular-weight heterogeneous complexes. Mol Cell 2009; 34:591-602.

3 Shih VF, Kearns JD, Basak S, et al. Kinetic control of negative feedback regulators of NF-kappaB/RelA determines their pathogen- and cytokine-receptor signaling specificity. Proc Natl Acad Sci USA 2009; 106:9619-9624.

4 Scheidereit C. IkappaB kinase complexes: gateways to NF-kappaB activation and transcription. Oncogene 2006; 25:6685-6705.

5 Rudolph D, Yeh WC, Wakeham A, et al. Severe liver degeneration and lack of NF-kappaB activation in NEMO/ IKKgamma-deficient mice. Genes Dev 2000; 14:854-862.

6 Li Q, Van Antwerp D, Mercurio F, Lee KF, Verma IM. Severe liver degeneration in mice lacking the IkappaB kinase 2 gene. Science 1999; 284:321-325.

7 Beg AA, Sha WC, Bronson RT, Ghosh S, Baltimore D. Embryonic lethality and liver degeneration in mice lacking the RelA component of NF-kappa B. Nature 1995; 376:167-170. 
8 Luedde T, Heinrichsdorff J, de Lorenzi R, et al. IKK1 and IKK2 cooperate to maintain bile duct integrity in the liver. Proc Natl Acad Sci USA 2008; 105:9733-9738.

9 Beinke S, Robinson MJ, Hugunin M, Ley SC. Lipopolysaccharide activation of the TPL-2/MEK/extracellular signalregulated kinase mitogen-activated protein kinase cascade is regulated by IkappaB kinase-induced proteolysis of NFkappaB1 p105. Mol Cell Biol 2004; 24:9658-9667.

10 Delhase M, Hayakawa M, Chen Y, Karin M. Positive and negative regulation of IkappaB kinase activity through IKKbeta subunit phosphorylation. Science 1999; 284:309-313.

11 Ea CK, Deng L, Xia ZP, Pineda G, Chen ZJ. Activation of IKK by TNFalpha requires site-specific ubiquitination of RIP1 and polyubiquitin binding by NEMO. Mol Cell 2006; 22:245-257.

12 Xu M, Skaug B, Zeng W, Chen ZJ. A ubiquitin replacement strategy in human cells reveals distinct mechanisms of IKK activation by TNFalpha and IL-1beta. Mol Cell 2009; 36:302-314.

13 Poyet J-L, Srinivasula SM, Lin J-h, et al. Activation of the I $\kappa$ B kinases by RIP via IKK $\gamma /$ NEMO-mediated oligomerization. J Biol Chem 2000; 275:37966-37977.

14 Haas TL, Emmerich CH, Gerlach B, et al. Recruitment of the linear ubiquitin chain assembly complex stabilizes the TNF-R1 signaling complex and is required for TNF-mediated gene induction. Mol Cell 2009; 36:831-844.

15 Tokunaga F, Sakata S, Saeki Y, et al. Involvement of linear polyubiquitylation of NEMO in NF-kappaB activation. Nat Cell Biol 2009; 11:123-132.

16 Deng L, Wang C, Spencer E, et al. Activation of the IkappaB kinase complex by TRAF6 requires a dimeric ubiquitinconjugating enzyme complex and a unique polyubiquitin chain. Cell 2000; 103:351-361.

17 Chen ZJ, Parent L, Maniatis T. Site-specific phosphorylation of IkappaBalpha by a novel ubiquitination-dependent protein kinase activity. Cell 1996; 84:853-862.

18 Lamhamedi-Cherradi SE, Zheng S, Hilliard BA, et al. Transcriptional regulation of type I diabetes by NF-kappa B. $J$ Immunol 2003; 171:4886-4892.

19 Mason NJ, Liou HC, Hunter CA. T cell-intrinsic expression of c-Rel regulates Th1 cell responses essential for resistance to Toxoplasma gondii. J Immunol 2004; 172:3704-3711.

20 Ouaaz F, Arron J, Zheng Y, Choi Y, Beg AA. Dendritic cell development and survival require distinct NF-kappaB subunits. Immunity 2002; 16:257-270.

21 Wang J, Wang X, Hussain S, et al. Distinct roles of different NF-kappa B subunits in regulating inflammatory and T cell stimulatory gene expression in dendritic cells. J Immunol 2007; 178:6777-6788.

22 Carrasco D, Cheng J, Lewin A, et al. Multiple hemopoietic defects and lymphoid hyperplasia in mice lacking the transcriptional activation domain of the c-Rel protein. $J$ Exp Med 1998; 187:973-984.

23 Beg AA, Baltimore D. An essential role for NF-kappaB in preventing TNF-alpha-induced cell death. Science 1996; 274:782-784.

24 Doi TS, Marino MW, Takahashi T, et al. Absence of tumor necrosis factor rescues RelA-deficient mice from embryonic lethality. Proc Natl Acad Sci USA 1999; 96:2994-2999.
25 Alcamo E, Mizgerd JP, Horwitz BH, et al. Targeted mutation of TNF receptor I rescues the RelA-deficient mouse and reveals a critical role for NF-kappa B in leukocyte recruitment. J Immunol 2001; 167:1592-1600.

26 Grossmann M, Metcalf D, Merryfull J, et al. The combined absence of the transcription factors Rel and RelA leads to multiple hemopoietic cell defects. Proc Natl Acad Sci USA 1999; 96:11848-11853.

27 Gugasyan R, Voss A, Varigos G, et al. The transcription factors c-rel and RelA control epidermal development and homeostasis in embryonic and adult skin via distinct mechanisms. Mol Cell Biol 2004; 24:5733-5745.

28 Senftleben U, Li ZW, Baud V, Karin M. IKKbeta is essential for protecting $\mathrm{T}$ cells from TNFalpha-induced apoptosis. Immunity 2001; 14:217-230.

29 Prendes M, Zheng Y, Beg AA. Regulation of developing B cell survival by RelA-containing NF-kappa B complexes. $J$ Immunol 2003; 171:3963-3969.

30 Bonnard M, Mirtsos C, Suzuki S, et al. Deficiency of T2K leads to apoptotic liver degeneration and impaired NF-kappaB-dependent gene transcription. EMBO J 2000; 19:49764985.

31 Sanjabi S, Hoffmann A, Liou HC, Baltimore D, Smale ST. Selective requirement for c-Rel during IL-12 P40 gene induction in macrophages. Proc Natl Acad Sci USA 2000; 97:12705-12710.

32 Hoffmann A, Leung TH, Baltimore D. Genetic analysis of NF-kappaB/Rel transcription factors defines functional specificities. EMBO J 2003; 22:5530-5539.

33 Leung TH, Hoffmann A, Baltimore D. One nucleotide in a kappaB site can determine cofactor specificity for NFkappaB dimers. Cell 2004; 118:453-464.

34 Sanjabi S, Williams KJ, Saccani S, et al. A c-Rel subdomain responsible for enhanced DNA-binding affinity and selective gene activation. Genes Dev 2005; 19:2138-2151.

35 Chen-Park FE, Huang DB, Noro B, Thanos D, Ghosh G. The kappa B DNA sequence from the HIV long terminal repeat functions as an allosteric regulator of HIV transcription. J Biol Chem 2002; 277:24701-24708.

36 Beg AA, Sha WC, Bronson RT, Baltimore D. Constitutive NF-kappa B activation, enhanced granulopoiesis, and neonatal lethality in I kappa B alpha-deficient mice. Genes Dev 1995; 9:2736-2746.

37 Peng B, Ling J, Lee AJ, et al. Defective feedback regulation of NF-kappaB underlies Sjogren's syndrome in mice with mutated kappaB enhancers of the IkappaBalpha promoter. Proc Natl Acad Sci USA 2010; 107:15193-15198.

38 Memet S, Laouini D, Epinat JC, et al. IkappaBepsilondeficient mice: reduction of one $\mathrm{T}$ cell precursor subspecies and enhanced Ig isotype switching and cytokine synthesis. $J$ Immunol 1999; 163:5994-6005.

39 Samson SI, Memet S, Vosshenrich CA, et al. Combined deficiency in IkappaBalpha and IkappaBepsilon reveals a critical window of NF-kappaB activity in natural killer cell differentiation. Blood 2004; 103:4573-4580.

40 O'Dea EL, Barken D, Peralta RQ, et al. A homeostatic model of IkappaB metabolism to control constitutive NF-kappaB activity. Mol Syst Biol 2007; 3:111.

41 Bergqvist S, Alverdi V, Mengel B, et al. Kinetic enhance- 


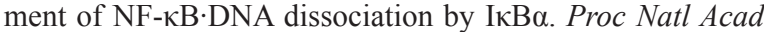
Sci USA 2009; 106:19328-19333.

42 Wertz IE, O'Rourke KM, Zhou H, et al. De-ubiquitination and ubiquitin ligase domains of A20 downregulate NFkappaB signalling. Nature 2004; 430:694-699.

43 Werner SL, Kearns JD, Zadorozhnaya V, et al. Encoding NF-kappaB temporal control in response to TNF: distinct roles for the negative regulators IkappaBalpha and A20. Genes Dev 2008; 22:2093-2101.

44 Saccani S, Marazzi I, Beg AA, Natoli G. Degradation of promoter-bound $\mathrm{p} 65 / \mathrm{RelA}$ is essential for the prompt termination of the nuclear factor kappaB response. $J$ Exp Med 2004; 200:107-113.

45 Liu B, Yang R, Wong KA, et al. Negative regulation of NFkappaB signaling by PIAS1. Mol Cell Biol 2005; 25:11131123.

46 Tahk S, Liu B, Chernishof V, et al. Control of specificity and magnitude of NF-kappa B and STAT1-mediated gene activation through PIASy and PIAS1 cooperation. Proc Natl Acad Sci USA 2007; 104:11643-11648.

47 Lawrence T, Bebien M, Liu GY, Nizet V, Karin M. IKKalpha limits macrophage NF-kappaB activation and contributes to the resolution of inflammation. Nature 2005; 434:11381143 .

48 Hoffmann A, Levchenko A, Scott ML, Baltimore D. The IkappaB-NF-kappaB signaling module: temporal control and selective gene activation. Science 2002; 298:1241-1245.

49 Kearns JD, Basak S, Werner SL, Huang CS, Hoffmann A. IkappaBepsilon provides negative feedback to control NFkappaB oscillations, signaling dynamics, and inflammatory gene expression. J Cell Biol 2006; 173:659-664.

50 Nelson DE, Ihekwaba AE, Elliott M, et al. Oscillations in NF-kappaB signaling control the dynamics of gene expression. Science 2004; 306:704-708.

51 Ashall L, Horton CA, Nelson DE, et al. Pulsatile stimulation determines timing and specificity of NF-kappaB-dependent transcription. Science 2009; 324:242-246.

52 Paszek P, Jackson DA, White MR. Oscillatory control of signalling molecules. Curr Opin Genet Dev 2010; doi:10.1016/ j.gde.2010.08.004.

53 Werner SL, Barken D, Hoffmann A. Stimulus specificity of gene expression programs determined by temporal control of IKK activity. Science 2005; 309:1857-1861.

54 Covert MW, Leung TH, Gaston JE, Baltimore D. Achieving stability of lipopolysaccharide-induced NF-kappaB activation. Science 2005; 309:1854-1857.

55 Behar M, Hoffmann A. Understanding the temporal codes of intra-cellular signals. Curr Opin Genet Dev 2010 Oct 16; doi:10.1016/j.gde.2010.09.007

56 Mathes E, O’Dea EL, Hoffmann A, Ghosh G. NF-kappaB dictates the degradation pathway of IkappaBalpha. EMBO J 2008; 27:1357-1367.

57 Mathes E, Wang L, Komives E, Ghosh G. Flexible regions within I\{kappa\} B \{alpha\} create the ubiquitin-independent degradation signal. J Biol Chem 2010; 285:32927-36.

58 O'Dea EL, Kearns JD, Hoffmann A. UV as an amplifier rather than inducer of NF-kappaB activity. Mol Cell 2008; 30:632-641.

59 Claudio E, Brown K, Park S, Wang H, Siebenlist U. BAFF- induced NEMO-independent processing of NF-kappa B2 in maturing B cells. Nat Immunol 2002; 3:958-965.

60 Zarnegar BJ, Wang Y, Mahoney DJ, et al. Noncanonical NF-kappaB activation requires coordinated assembly of a regulatory complex of the adaptors cIAP1, cIAP2, TRAF2 and TRAF3 and the kinase NIK. Nat Immunol 2008; 9:13711378.

61 Vallabhapurapu S, Matsuzawa A, Zhang W, et al. Nonredundant and complementary functions of TRAF2 and TRAF3 in a ubiquitination cascade that activates NIK-dependent alternative NF-kappaB signaling. Nat Immunol 2008; 9:13641370.

62 He JQ, Zarnegar B, Oganesyan G, et al. Rescue of TRAF3null mice by p100 NF-kappa B deficiency. $J$ Exp Med 2006; 203:2413-2418.

63 Liao G, Zhang M, Harhaj EW, Sun SC. Regulation of the NF-kappaB-inducing kinase by tumor necrosis factor receptor-associated factor 3-induced degradation. $\mathrm{J}$ Biol Chem 2004; 279:26243-26250.

64 Senftleben U, Cao Y, Xiao G, et al. Activation by IKKalpha of a second, evolutionary conserved, NF-kappa B signaling pathway. Science 2001; 293:1495-1499.

65 Xiao G, Harhaj EW, Sun SC. NF-kappaB-inducing kinase regulates the processing of NF-kappaB2 p100. Mol Cell 2001; 7:401-409.

66 Xiao G, Fong A, Sun SC. Induction of p100 processing by NF-kappaB-inducing kinase involves docking IkappaB kinase alpha (IKKalpha) to p100 and IKKalpha-mediated phosphorylation. J Biol Chem 2004; 279:30099-30105.

67 Mordmuller B, Krappmann D, Esen M, Wegener E, Scheidereit $\mathrm{C}$. Lymphotoxin and lipopolysaccharide induce NF-kappaB-p52 generation by a co-translational mechanism. EMBO Rep 2003; 4:82-87.

68 Derudder E, Dejardin E, Pritchard LL, et al. RelB/p50 dimers are differentially regulated by tumor necrosis factor-alpha and lymphotoxin-beta receptor activation: critical roles for p100. J Biol Chem 2003; 278:23278-23284.

69 Fusco AJ, Savinova OV, Talwar R, et al. Stabilization of RelB requires multidomain interactions with p100/p52. J Biol Chem 2008; 283:12324-12332.

70 Basak S, Shih VF, Hoffmann A. Generation and activation of multiple dimeric transcription factors within the NF-kappaB signaling system. Mol Cell Biol 2008; 28:3139-3150.

71 Razani B, Zarnegar B, Ytterberg AJ, et al. Negative feedback in noncanonical NF-kappaB signaling modulates NIK stability through IKKalpha-mediated phosphorylation. Sci Signal 2010; 3:ra41.

72 Li T, Morgan MJ, Choksi S, et al. MicroRNAs modulate the noncanonical transcription factor NF-kappaB pathway by regulating expression of the kinase IKKalpha during macrophage differentiation. Nat Immunol 11:799-805.

73 Marienfeld R, Berberich-Siebelt F, Berberich I, et al. Signalspecific and phosphorylation-dependent RelB degradation: a potential mechanism of NF-kappaB control. Oncogene 2001; 20:8142-8147.

74 Weih F, Caamano J. Regulation of secondary lymphoid organ development by the nuclear factor-kappaB signal transduction pathway. Immunol Rev 2003; 195:91-105.

75 Yilmaz ZB, Weih DS, Sivakumar V, Weih F. RelB is re- 
quired for Peyer's patch development: differential regulation of p52-RelB by lymphotoxin and TNF. EMBO J 2003; 22:121-130.

76 Yin L, Wu L, Wesche H, et al. Defective lymphotoxin-beta receptor-induced NF-kappaB transcriptional activity in NIKdeficient mice. Science 2001; 291:2162-2165.

77 Shinkura R, Kitada K, Matsuda F, et al. Alymphoplasia is caused by a point mutation in the mouse gene encoding Nfkappa b-inducing kinase. Nat Genet 1999; 22:74-77.

78 Fagarasan S, Shinkura R, Kamata T, et al. Alymphoplasia (aly)-type nuclear factor kappaB-inducing kinase (NIK) causes defects in secondary lymphoid tissue chemokine receptor signaling and homing of peritoneal cells to the gut-associated lymphatic tissue system. J Exp Med 2000; 191:1477-1486.

79 Caamano JH, Rizzo CA, Durham SK, et al. Nuclear factor (NF)-kappa B2 (p100/p52) is required for normal splenic microarchitecture and B cell-mediated immune responses. $J$ Exp Med 1998; 187:185-196.

80 Franzoso G, Carlson L, Poljak L, et al. Mice deficient in nuclear factor (NF)-kappa B/p52 present with defects in humoral responses, germinal center reactions, and splenic microarchitecture. J Exp Med 1998; 187:147-159.

81 Weih DS, Yilmaz ZB, Weih F. Essential role of RelB in germinal center and marginal zone formation and proper expression of homing chemokines. J Immunol 2001; 167:19091919.

82 Cao Y, Bonizzi G, Seagroves TN, et al. IKKalpha provides an essential link between RANK signaling and cyclin D1 expression during mammary gland development. Cell 2001; 107:763-775.

83 Demicco EG, Kavanagh KT, Romieu-Mourez R, et al. RelB/p52 NF-kappaB complexes rescue an early delay in mammary gland development in transgenic mice with targeted suppressor IkappaB-alpha expression and promote carcinogenesis of the mammary gland. Mol Cell Biol 2005; 25:10136-10147.

84 Vaira S, Johnson T, Hirbe AC, et al. RelB is the NF-kappaB subunit downstream of NIK responsible for osteoclast differentiation. Proc Natl Acad Sci USA 2008; 105:3897-3902.

$85 \mathrm{Wu} \mathrm{L}, \mathrm{D}$ 'Amico A, Winkel KD, et al. RelB is essential for the development of myeloid-related CD8alpha- dendritic cells but not of lymphoid-related CD8alpha+ dendritic cells. Immunity 1998; 9:839-847.

86 Carrasco D, Ryseck RP, Bravo R. Expression of relB transcripts during lymphoid organ development: specific expression in dendritic antigen-presenting cells. Development 1993; 118:1221-1231.

87 Kobayashi T, Walsh PT, Walsh MC, et al. TRAF6 is a critical factor for dendritic cell maturation and development. Immunity 2003; 19:353-363.

88 Dejardin E, Droin NM, Delhase M, et al. The lymphotoxinbeta receptor induces different patterns of gene expression via two NF-kappaB pathways. Immunity 2002; 17:525-535.

89 Bonizzi G, Bebien M, Otero DC, et al. Activation of IKKalpha target genes depends on recognition of specific kappaB binding sites by RelB:p52 dimers. EMBO J 2004; 23:42024210.

90 Lovas A, Radke D, Albrecht D, et al. Differential RelA- and
RelB-dependent gene transcription in LTbetaR-stimulated mouse embryonic fibroblasts. BMC Genomics 2008; 9:606.

91 Britanova LV, Makeev VJ, Kuprash DV. In vitro selection of optimal RelB/p52 DNA-binding motifs. Biochem Biophys Res Commun 2008; 365:583-588.

92 Sasaki Y, Derudder E, Hobeika E, et al. Canonical NF-kappaB activity, dispensable for B cell development, replaces BAFF-receptor signals and promotes B cell proliferation upon activation. Immunity 2006; 24:729-739.

93 Moorthy AK, Huang DB, Wang VY, Vu D, Ghosh G. X-ray structure of a NF-kappaB p50/RelB/DNA complex reveals assembly of multiple dimers on tandem kappaB sites. $J$ Mol Biol 2007; 373:723-734.

94 Fusco AJ, Huang DB, Miller D, et al. NF-kappaB p52:RelB heterodimer recognizes two classes of kappaB sites with two distinct modes. EMBO Rep 2009; 10:152-159.

95 Pomerantz JL, Baltimore D. Two pathways to NF-kappaB. Mol Cell 2002; 10:693-695.

96 Mercurio F, DiDonato JA, Rosette C, Karin M. p105 and p98 precursor proteins play an active role in NF-kappa Bmediated signal transduction. Genes Dev 1993; 7:705-718.

97 Tucker E, O'Donnell K, Fuchsberger M, et al. A novel mutation in the $N f k b 2$ gene generates an NF-kappa B2 "super repressor". J Immunol 2007; 179:7514-7522.

98 Novack DV, Yin L, Hagen-Stapleton A, et al. The IkappaB function of NF-kappaB2 p100 controls stimulated osteoclastogenesis. J Exp Med 2003; 198:771-781.

99 Ishimaru N, Kishimoto H, Hayashi Y, Sprent J. Regulation of naive $\mathrm{T}$ cell function by the NF-kappaB2 pathway. Nat Immunol 2006; 7:763-772.

100 Courtois G, Gilmore TD. Mutations in the NF-kappaB signaling pathway: implications for human disease. Oncogene 2006; 25:6831-6843.

101 Neri A, Fracchiolla NS, Migliazza A, Trecca D, Lombardi L. The involvement of the candidate proto-oncogene NFKB2/ lyt-10 in lymphoid malignancies. Leuk Lymphoma 1996; 23:43-48.

102 Annunziata CM, Davis RE, Demchenko Y, et al. Frequent engagement of the classical and alternative NF-kappaB pathways by diverse genetic abnormalities in multiple myeloma. Cancer Cell 2007; 12:115-130.

103 Keats JJ, Fonseca R, Chesi M, et al. Promiscuous mutations activate the noncanonical NF-kappaB pathway in multiple myeloma. Cancer Cell 2007; 12:131-144.

104 Malinin NL, Boldin MP, Kovalenko AV, Wallach D. MAP3K-related kinase involved in NF-kappaB induction by TNF, CD95 and IL-1. Nature 1997; 385:540-544.

105 Bren GD, Solan NJ, Miyoshi H, et al. Transcription of the RelB gene is regulated by NF-kappaB. Oncogene 2001; 20:7722-7733.

106 Liptay S, Schmid RM, Nabel EG, Nabel GJ. Transcriptional regulation of NF-kappa B2: evidence for kappa B-mediated positive and negative autoregulation. Mol Cell Biol 1994; 14:7695-7703.

107 Muller JR, Siebenlist U. Lymphotoxin beta receptor induces sequential activation of distinct NF-kappa B factors via separate signaling pathways. J Biol Chem 2003; 278:1200612012.

108 Alcamo E, Hacohen N, Schulte LC, et al. Requirement for 
the NF-kappaB family member RelA in the development of secondary lymphoid organs. J Exp Med 2002; 195:233-244.

109 Lo JC, Basak S, James ES, et al. Coordination between NFkappaB family members p50 and p52 is essential for mediating LTbetaR signals in the development and organization of secondary lymphoid tissues. Blood 2006; 107:1048-1055.

110 Sha WC, Liou HC, Tuomanen EI, Baltimore D. Targeted disruption of the p50 subunit of NF-kappa B leads to multifocal defects in immune responses. Cell 1995; 80:321-330. 